\title{
openheart Switching between thienopyridines in patients with acute myocardial infarction and quality of care
}

Francois Schiele, ${ }^{1}$ Etienne Puymirat, ${ }^{2}$ Laurent Bonello, ${ }^{3}$ Nicolas Meneveau, ${ }^{1}$ Jean-Philippe Collet, ${ }^{4}$ Pascal Motreff, ${ }^{5,6}$ Ramin Ravan, ${ }^{7}$ Florence Leclercq, ${ }^{8}$ Pierre-Vladimir Ennezat, ${ }^{9}$ Jean Ferrières, ${ }^{10}$ Tabassome Simon, ${ }^{11}$ Nicolas Danchin ${ }^{12}$

To cite: Schiele $F$, Puymirat E, Bonello L, et al. Switching between thienopyridines in patients with acute myocardial infarction and quality of care. Open Heart 2016;3:e000384. doi:10.1136/openhrt-2015000384

Received 11 December 2015 Revised 8 April 2016 Accepted 25 April 2016

\section{CrossMark}

For numbered affiliations see end of article.

\section{Correspondence to}

Professor Francois Schiele; francois.schiele@univ-fcomte. $\mathrm{fr}$

\section{ABSTRACT}

Objective: In acute coronary syndromes, switching between thienopyridines is frequent. The aims of the study were to assess the association between switching practices and quality of care.

Methods: Registry study performed in 213 French public university, public non-academic and private hospitals. All consecutive patients admitted for acute myocardial infarction ( $\mathrm{Ml} ;<48$ hours) between 1/10/2010 and 30/11/2010 were eligible. Clinical and biological data were recorded up to 12 months follow-up.

Results: Among 4101 patients receiving thienopyridines, a switch was performed in 868 (21.2\%): $678(16.5 \%)$ from clopidogrel to prasugrel and 190 $(4.6 \%)$ from prasugrel to clopidogrel. Predictors of switch were ST segment elevation MI presentation, admission to a cardiology unit, previous percutaneous coronary intervention, younger age, body weight $>60 \mathrm{~kg}$, no history of stroke, cardiac arrest, anaemia or renal dysfunction. In patients with a switch, eligibility for prasugrel was $>82 \%$ and appropriate use of a switch was $86 \%$ from clopidogrel to prasugrel and $20 \%$ from prasugrel to clopidogrel. Quality indicators scored higher in the group with a switch and also in centres where the switch rate was higher.

Conclusions: As applied in the French Registry on Acute ST-elevation and non ST-elevation Myocardial Infarction (FAST-MI) registry, switching from one P2Y12 inhibitor to another led to a more appropriate prescription and was associated with higher scores on indicators of quality of care.

\section{INTRODUCTION}

Changing a patient's treatment and management in the light of new information or clinical changes is often mandatory in routine practice. In the setting of acute coronary syndromes (ACS), dual antiplatelet therapy (DAPT) is recommended as early as possible, and the initial thienopyridine is chosen according to drug labelling and available clinical information. During the in-hospital phase, more information becomes available to the physician, ${ }^{1}$ and the initial choice of

\section{KEY QUESTIONS}

What is already known about this subject?

- The choice between clopidogrel and prasugrel is based on patient characteristics and management. In some clinical situations, the initia choice may be suboptimal and a switch between molecules may be performed. The relation between the rate of switching and indicators of quality of care has never been investigated.

What does this study add?

- This study informs on the rates of switching practices, showing that it is quite frequent (around $21.2 \%$ of patients). We further report that in a large nationwide registry of over 4000 patients, this practice was not associated with misuse of thienopyridines, but with higher scores on indicators of quality of care.

How might this impact on clinical practice?

- The findings of this study indicate that patients may safely be switched from clopidogrel to prasugrel or vice versa, to allow optimum therapy in accordance with the indications for each patient.

treatment may come to be considered as suboptimal. Customisation of oral antiplatelet treatment can prompt a switch from one drug to another. In a large registry study, among 40531 patients initially treated with clopidogrel, $5.2 \%$ were switched to prasugrel and $11.5 \%$ of those with an initial prescription of prasugrel were discharged under clopidogrel. ${ }^{2-4}$ Nevertheless, the appropriateness of these switches and their association with quality of care is poorly documented. We use data from French Registry on Acute ST-elevation and non ST-elevation Myocardial Infarction (FAST-MI) 2010, a nationwide multicentre registry of patients admitted for acute myocardial infarction (AMI) in France, ${ }^{5}$ (1) to determine the rate and predictors of switching between clopidogrel and prasugrel and vice versa; (2) to assess the 
appropriateness of the choice of thienopyridine; and (3) to assess the association between switch rate and quality of care by centre.

\section{METHODS}

\section{Data sources and population}

The population and methods of the FAST-MI 2010 registry have been described previously. ${ }^{5}$ Briefly, all consecutive patients admitted for AMI ( $<48$ hours) between 1 October and 30 November 2010 in 213 French hospitals were eligible for inclusion. Data collected included the Cardiology Audit and Registration Data System data set $^{6}$ as well as a number of additional variables, and data from clinical follow-up were recorded up to 12 months. A centralised electronic case report form was used, and the quality of data was monitored by automatic data checks and independent external research assistants.

Written informed consent was provided by each patient for participation in the study. The study was conducted in compliance with Good Clinical Practice, French legislation and French data protection laws. The protocol was reviewed and approved by the Committee for the Protection of Human Subjects of Saint Louis University Hospital Paris Ile de France IV, Paris, France.

\section{Definitions}

Switch: Use of thienopyridines was collected at four time points (prehospital, admission-24 hours, 24-48 hours and discharge). Any change in thienopyridines during hospitalisation was recorded as a switch (regardless of the direction). Switches were also considered separately (ie, from clopidogrel to prasugrel, and from prasugrel to clopidogrel).

Eligibility for prasugrel was defined, according to the French labelling, as patients with ACS, without history of stroke or transient ischaemic attack (TIA), aged $<75$ years, body weight $\geq 60 \mathrm{~kg}$, and intended for percutaneous coronary intervention (PCI; to define eligibility at admission) or PCI actually performed (to define eligibility at discharge).

Appropriate use of a switch in thienopyridines was defined as (1) non-eligibility for the first thienopyridine, (2) bleeding or thrombotic event related to the admission thienopyridine or (3) expectation of potential clinical benefit, supported by the results of clinical randomised trials (ie, switch from clopidogrel to prasugrel in patients eligible for prasugrel, as shown in the TRITON study, ${ }^{7}$ or switch from prasugrel to clopidogrel in patients treated without PCI, as shown in the TRILOGY study). ${ }^{8}$

Quality of care: Quality indicators were defined for each centre as the rate of use, at discharge, of DAPT, $\beta$-blockers, ACE inhibitors and statins, irrespective of potential contraindications; and, for patients with ST segment elevation MI (STEMI), as the rate of use of reperfusion and the rate of timely reperfusion (ie, reperfusion within $120 \mathrm{~min}$ by primary PCI or within $60 \mathrm{~min}$ by thrombolysis). A composite indicator was calculated using opportunity scoring (one point by applicable indicator divided by the number of applicable indicators).

\section{Statistics}

Categorical variables are presented as number of cases (percentage), continuous non-normally distributed

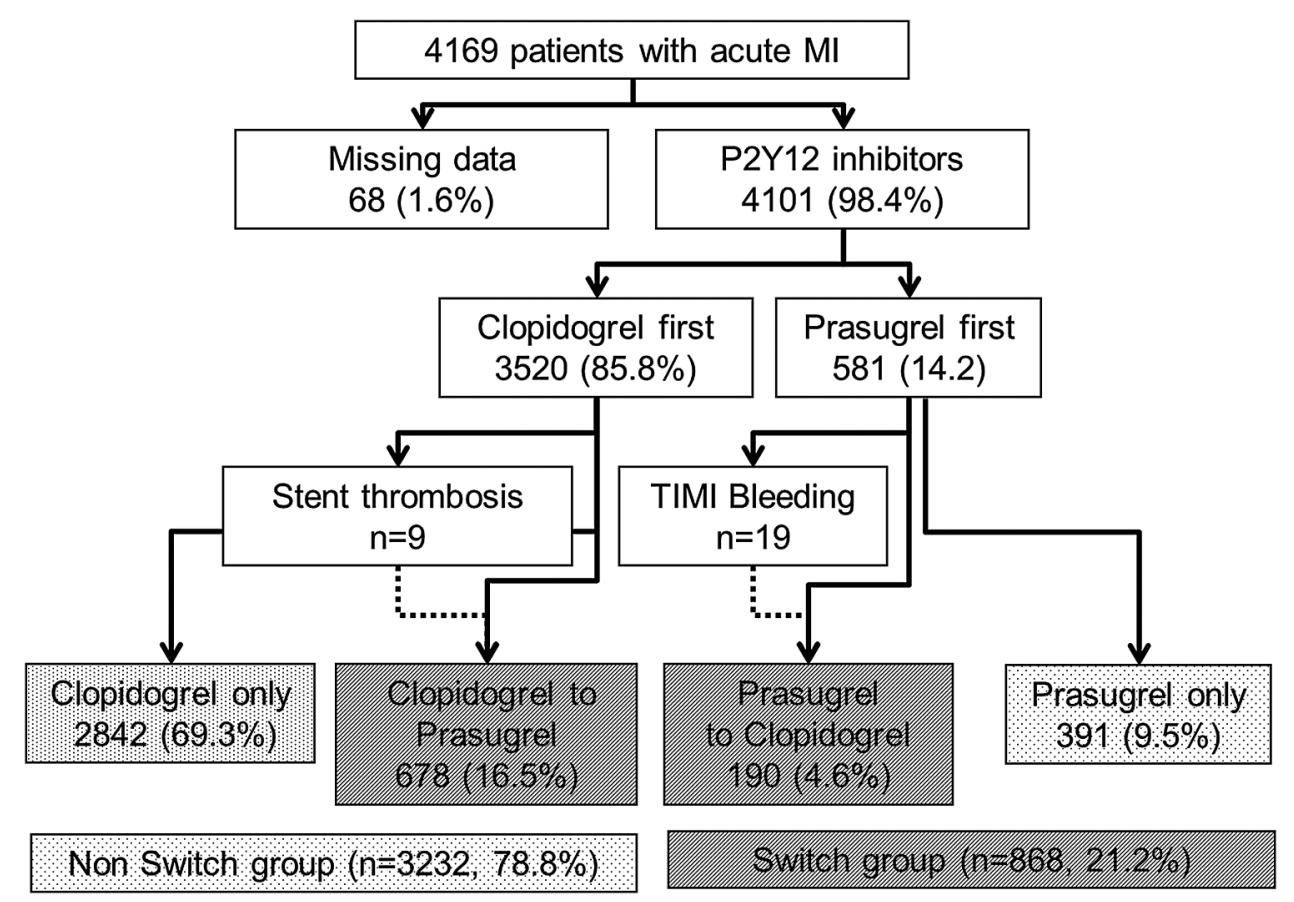

Figure 1 Flow chart of the study population according to thienopyridines used in the FAST-MI registry in patients with STEMI and NSTEMI. FAST-MI, French Registry on Acute ST-elevation and non ST-elevation Myocardial Infarction; MI, myocardial infarction; NSTEMI, non-ST segment elevation myocardial infarction; STEMI, ST segment elevation myocardial infarction. 


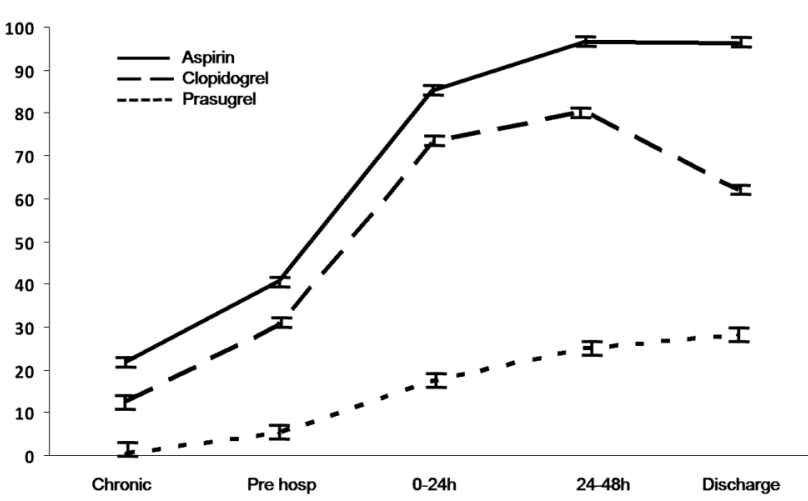

Figure 2 Proportion of patients receiving oral antiplatelet agents at each time point (pretreatment, prehospital, admission to 24 hours, 24-48 hours and at discharge).

variables as median (IQR), and continuous normally distributed variables as mean \pm SD.

Description of switching practices: We report the rate, timing and modalities of switches in the whole population and by centre.

Predictors of switching (any switch, regardless of the direction) were identified by logistic regression. Variables introduced into the model were age (by quartiles), body weight ( $\geq$ or $<60 \mathrm{~kg}$ ), type of MI, symptoms at presentation (chest pain, dyspnoea, cardiac arrest or other), cardiovascular risk factors (hypertension, diabetes, hypercholesterolaemia, smoking), history (of angina, MI, percutaneous or surgical revascularisation, stroke, peripheral artery disease, heart failure, cancer, Alzheimer's disease), chronic treatment with aspirin, $\beta$-blockers, ACE inhibitors (or angiotensin receptor blockers), statins, insulin, nitrates or oral anticoagulation, haemodynamic conditions at admission (all components of the Global Registry of Acute Coronary Events (GRACE) risk score, sinus rhythm, atrioventricular block) and biological variables (glucose and haemoglobin levels). We also used centre-related variables such as university versus community hospital, high versus low volume (characterised according to the median annual number of admissions for AMI) and availability of a catheterisation laboratory on site or not. A stepwise approach was used, with a threshold of $<0.05$ for entry and for remaining in the model.

Quality of care indicators associated with switching: Centres were categorised into four groups according to the rate of use of switch (by quartiles): between $0 \%$ and $7 \%, 8-18 \%, 19-33 \%$ and above $33 \%$. We compared indicators of quality of care across the four centre groups. To compare quality indicators between categories, trend analyses were performed using the Cochran Armitage

Table 1 Eligibility criteria for $\mathrm{P}$, and appropriate choice of $\mathrm{C}$ or $\mathrm{P}$ at admission and at discharge in the four groups

\begin{tabular}{|c|c|c|c|c|}
\hline & $\begin{array}{l}\mathrm{C} \\
\mathrm{N}=2842(69.3 \%)\end{array}$ & $\begin{array}{l}P \\
N=391(9.5 \%)\end{array}$ & $\begin{array}{l}\text { Switch } C \text { to } P \\
N=678(16.5 \%)\end{array}$ & $\begin{array}{l}\text { Switch P to C } \\
N=190(4.6 \%)\end{array}$ \\
\hline \multirow[t]{7}{*}{ Loading dose of the initial P2Y12 (in mg) } & C & $P$ & $\mathrm{C}$ & $\mathrm{P}$ \\
\hline & 75: $476(17 \%)$ & 5: $2(1 \%)$ & 75: $49(7 \%)$ & 10: 109 (57\%) \\
\hline & 150: $64(2 \%)$ & 10: $46(12 \%)$ & 150: $6(1 \%)$ & 30: $9(5 \%)$ \\
\hline & 300: 1361 (48\%) & 30: $10(2 \%)$ & 300: $322(47 \%)$ & 60: $47(25 \%)$ \\
\hline & 600: $851(30 \%)$ & 60: $325(83 \%)$ & 600: 253 (37\%) & ND: $25(13 \%)$ \\
\hline & $>600: 16(1 \%)$ & ND: $8(2 \%)$ & $>600: 12(2 \%)$ & \\
\hline & ND: $74(3 \%)$ & & ND: $36(5 \%)$ & \\
\hline \multirow[t]{7}{*}{ Loading dose of the final P2Y12 (in mg) } & & & $\mathrm{P}$ & $\mathrm{C}$ \\
\hline & & & 10: $397(59 \%)$ & 75: $31(16 \%)$ \\
\hline & & & 30: $23(3 \%)$ & 150: $4(2 \%)$ \\
\hline & & & 60: $56(8 \%)$ & $300: 51(27 \%)$ \\
\hline & & & ND: 202 (30\%) & 600: 78 (41\%) \\
\hline & & & & 600: $3(2 \%)$ \\
\hline & & & & ND: $23(12 \%)$ \\
\hline Intended PPCI* (STEMI) & $804(28.3 \%)$ & $253(64.7 \%)$ & $328(48.4 \%)$ & $110(57.9 \%)$ \\
\hline History of TIA or stroke & $179(6.3 \%)$ & $4(1.0 \%)$ & $8(1.2 \%)$ & 0 \\
\hline Body weight $\leq 60 \mathrm{~kg}$ & $361(13.3 \%)$ & $12(3.2 \%)$ & $16(2.4 \%)$ & $13(6.9 \%)$ \\
\hline Age $>75$ years & $1149(40.4 \%)$ & $11(2.8 \%)$ & $34(5.1 \%)$ & $7(3.7 \%)$ \\
\hline Eligible for $\mathrm{P}$ at admission $†$ & $425(14.9 \%)$ & $233(59.6 \%)$ & $291(42.9 \%)$ & $98(51.6 \%)$ \\
\hline No PCI (all Mls) & $782(27.5 \%)$ & $27(6.9 \%)$ & $33(4.9 \%)$ & $14(7.4 \%)$ \\
\hline Eligible for $\mathrm{P}$ at discharge $\ddagger$ & $1119(39.4 \%)$ & $327(83.6 \%)$ & $584(86.1 \%)$ & $156(82.1 \%)$ \\
\hline §Appropriate use of switch & & & $584(86 \%)$ & $38(20 \%)$ \\
\hline \multicolumn{5}{|c|}{$\begin{array}{l}\text { *Intended PPCI: patients admitted for STEMI for whom reperfusion with primary angioplasty was intended. } \\
\dagger \text { Eligible for } \mathrm{P} \text { at admission: patients with acute coronary syndrome, body weight }>60 \mathrm{~kg} \text {, age }<76 \text { years, without history of stroke or TIA and } \\
\text { intended for PPCl. } \\
\text { †Eligible for } \mathrm{P} \text { at discharge: patients with acute coronary syndrome, treated with } \mathrm{PCl} \text {, age }<76 \text { years, body weight }>60 \mathrm{~kg} \text {, without history of } \\
\text { stroke or TIA, and with no major or moderate bleeding during hospitalisation. } \\
\text { §Appropriate use of C/P at discharge: patients not eligible for } \mathrm{P} \text {, discharged with } \mathrm{C} \text { or patients eligible for } \mathrm{P} \text {, discharged with } \mathrm{P} \text {. } \\
\mathrm{C} \text {, clopidogrel; Mls, myocardial infarction; } \mathrm{P} \text {, prasugrel; } \mathrm{PPCl} \text {, primary percutaneous coronary intervention; STEMI, ST elevation myocardial } \\
\text { infarction; TIA, transient ischaemic attack. }\end{array}$} \\
\hline
\end{tabular}


test for qualitative variables or the Jonckheere-Terpstra test for quantitative variables.

All tests were two sided, and a $\mathrm{p}$ value $<0.05$ was considered significant. All analyses were performed using SAS software, V.9.2 (SAS Institute Inc, Cary, North Carolina, USA).

\section{RESULTS}

\section{Study population}

Among 4970 patients screened in 213 participating centres, 552 were excluded because they did not meet the criteria for AMI, and 249 refused to participate. Overall, 4169 patients were eligible, of whom 4101 received thienopyridines at admission (3520 (85.8\%) clopidogrel, 581 (14.2\%) prasugrel). The use of prasugrel as initial thienopyridine was related to the type of MI (437 (19.8\%) patients with STEMI and 144 (7.5\%) patients with non-STEMI (NSTEMI)). During hospitalisation, $3233(78.8 \%)$ patients had no switch: 2842 $(69.3 \%)$ were treated with clopidogrel and $391(9.5 \%)$ with prasugrel. Conversely, $868(21.2 \%)$ patients had a switch during hospitalisation: $678 \quad(16.5 \%)$ from

Table 2 Baseline characteristics, conditions at admission, management and outcomes according to P2Y12 use during hospitalisation in the FAST-MI registry

\begin{tabular}{|c|c|c|c|c|}
\hline Variable & $\begin{array}{l}\mathrm{C} \\
\mathrm{N}=2842(69.3 \%)\end{array}$ & $\begin{array}{l}\mathrm{P} \\
\mathrm{N}=391(9.5 \%)\end{array}$ & $\begin{array}{l}\text { Switch } C \text { to } P \\
N=678(16.5 \%)\end{array}$ & $\begin{array}{l}\text { Switch P to C } \\
N=190(4.6 \%)\end{array}$ \\
\hline Male gender & $1913(67.3 \%)$ & $348(89.0 \%)$ & $573(84.5 \%)$ & $158(83.2 \%)$ \\
\hline Age, years & $68 \pm 14$ & $56 \pm 11$ & $56 \pm 11$ & $56 \pm 11$ \\
\hline STEMI & $1303(45.8 \%)$ & $295(75.4 \%)$ & $472(69.6 \%)$ & $143(75.3 \%)$ \\
\hline Hypertension & 1699 (59.8\%) & $144(36.8 \%)$ & $286(42.2 \%)$ & $57(30.0 \%)$ \\
\hline Hypercholesterolaemia & $1250(44.0 \%)$ & $154(39.4 \%)$ & $295(43.5 \%)$ & $80(42.1 \%)$ \\
\hline Current smoking & $780(27.4 \%)$ & $201(51.4 \%)$ & $364(53.7 \%)$ & $106(55.8 \%)$ \\
\hline Diabetes & $628(22.1 \%)$ & $46(11.8 \%)$ & 107 (15.8\%) & $35(18.4 \%)$ \\
\hline Body weight, kg & $75 \pm 15$ & $80 \pm 14$ & $82 \pm 14$ & $81 \pm 18$ \\
\hline Prior MI & $489(17.2 \%)$ & $30(7.7 \%)$ & 97 (14.3\%) & $10(5.3 \%)$ \\
\hline Prior PCl & 457 (16.1\%) & $37(9.5 \%)$ & $108(15.9 \%)$ & $13(6.8 \%)$ \\
\hline Prior CABG & 189 (6.7\%) & $20(5.1 \%)$ & $28(4.1 \%)$ & $9(4.7 \%)$ \\
\hline History of HF & $156(5.5 \%)$ & $2(0.5 \%)$ & $11(1.6 \%)$ & $1(0.5 \%)$ \\
\hline History of stroke & $131(4.6 \%)$ & $3(0.8 \%)$ & $6(0.9 \%)$ & $0(0.0 \%)$ \\
\hline PAD & $269(9.5 \%)$ & $15(3.8 \%)$ & $31(4.6 \%)$ & $5(2.6 \%)$ \\
\hline CKD & $145(5.1 \%)$ & $4(1.0 \%)$ & $11(1.6 \%)$ & $1(0.5 \%)$ \\
\hline COPD & $195(6.9 \%)$ & $22(5.6 \%)$ & $37(5.5 \%)$ & $12(6.3 \%)$ \\
\hline Admission Killip>2 & $158(5.8 \%)$ & $7(1.9 \%)$ & $14(2.1 \%)$ & $2(1.1 \%)$ \\
\hline Admission SBP, mm Hg & $145 \pm 29$ & $142 \pm 27$ & $145 \pm 26$ & $144 \pm 28$ \\
\hline Admission HR, bpm & $80 \pm 21$ & $77 \pm 20$ & $77 \pm 19$ & $78 \pm 17$ \\
\hline Early GRACE score & $147 \pm 37$ & $127 \pm 26$ & $125 \pm 29$ & $126 \pm 30$ \\
\hline Creatinine, $\mathrm{mmol} / \mathrm{L}$ & $101 \pm 107$ & $90 \pm 57$ & $87 \pm 25$ & $83 \pm 24$ \\
\hline $\mathrm{GFR}, \mathrm{mL} / \mathrm{min}$ & $70 \pm 37$ & $89 \pm 28$ & $91 \pm 30$ & $96 \pm 40$ \\
\hline Admission to centre with on-site cathlab & $1933(68 \%)$ & $345(88.2 \%)$ & $500(73.7 \%)$ & $121(63.7 \%)$ \\
\hline Primary $\mathrm{PCl}$ & $804(58.5 \%)$ & $253(84.9 \%)$ & $328(69.5 \%)$ & $110(75.9 \%)$ \\
\hline Coronary angioplasty & $2060(72.4 \%)$ & $390(93.0 \%)$ & $645(95.1 \%)$ & $176(92.6 \%)$ \\
\hline Recurrent MI & $26(0.9 \%)$ & $3(0.8 \%)$ & $14(2.1 \%)$ & $1(0.5 \%)$ \\
\hline Stent thrombosis & $8(0.3 \%)$ & $3(0.8 \%)$ & $9(1.3 \%)$ & $1(0.5 \%)$ \\
\hline Major bleeding & $14(0.5 \%)$ & $3(0.8 \%)$ & $0(0.0 \%)$ & $1(0.5 \%)$ \\
\hline Fatal bleeding & $1(0.0 \%)$ & $0(0.0 \%)$ & $0(0.0 \%)$ & $0(0.0 \%)$ \\
\hline $\mathrm{Hb}$ drop of $3-5 \mathrm{~g} / \mathrm{dL}$ & $226(8.0 \%)$ & $20(5.1 \%)$ & $49(7.2 \%)$ & $17(8.9 \%)$ \\
\hline $\mathrm{Hb}$ drop $\geq 5 \mathrm{~g} / \mathrm{dL}$ & $60(2.1 \%)$ & $10(2.6 \%)$ & $6(0.9 \%)$ & $4(2.1 \%)$ \\
\hline BARC bleed type 3A & $46(1.6 \%)$ & $4(1.0 \%)$ & $10(1.5 \%)$ & $5(2.6 \%)$ \\
\hline BARC bleed type 3B & $70(2.5 \%)$ & $10(2.6 \%)$ & $6(0.9 \%)$ & $4(2.1 \%)$ \\
\hline BARC bleed type 3C & $2(0.1 \%)$ & $0(0.0 \%)$ & $0(0.0 \%)$ & $0(0.0 \%)$ \\
\hline Transfusion & $118(4.2 \%)$ & $4(1.0 \%)$ & $3(0.4 \%)$ & $3(1.6 \%)$ \\
\hline In-hospital death & $98(3.4 \%)$ & $2(0.5 \%)$ & $2(0.3 \%)$ & $1(0.5 \%)$ \\
\hline Combined end point* & $80(3.9 \%)$ & $2(0.8 \%)$ & $5(1.0 \%)$ & $1(0.8 \%)$ \\
\hline One-year all-cause mortality & $290(10.2 \%)$ & $5(1.3 \%)$ & $12(1.8 \%)$ & $2(1.1 \%)$ \\
\hline
\end{tabular}

${ }^{*}$ Combined end point=death, stent thrombosis, stroke and/or BARC type $\geq 3$ bleeding.

BARC, Bleeding Academic Research Consortium; C, clopidogrel; CABG, coronary artery bypass graft; CKD, chronic kidney disease; COPD, chronic obstructive pulmonary disease; FAST-MI, French Registry on Acute ST-elevation and non ST-elevation Myocardial Infarction; GFR, glomerular filtration rate estimated by the Cockroft-Gault formula; cathlab, catheterisation laboratory; GRACE, Global Registry of Acute Coronary Events; $\mathrm{Hb}$, haemoglobin; $\mathrm{HF}$, heart failure; $\mathrm{HR}$, heart rate; kg, kilograms; MI, myocardial infarction; $\mathrm{P}$, prasugrel; PAD, peripheral arterial disease; $\mathrm{PCl}$, percutaneous coronary intervention; SBP, systolic blood pressure; STEMI, ST segment elevation myocardial infarction. 


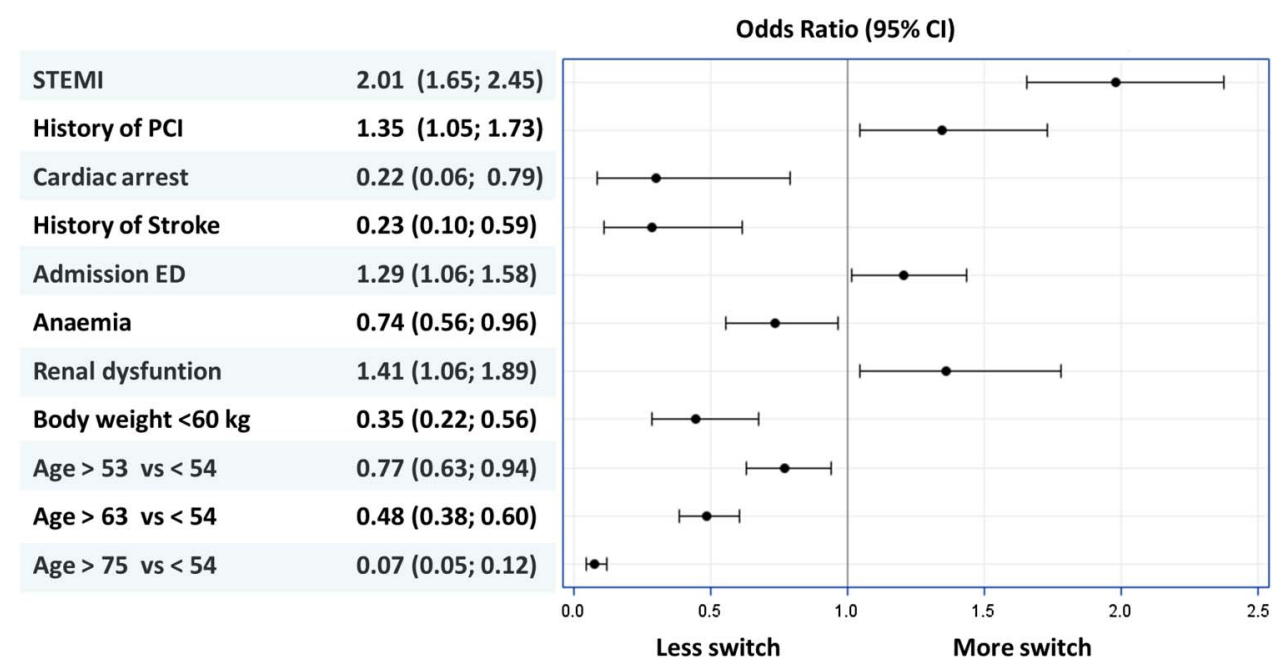

Figure 3 Forest plot of ORs for the predictors of switch in thienopyridines. STEMI, ST segment elevation myocardial infarction; $\mathrm{ED}$, emergency department; $\mathrm{PCl}$, percutaneous coronary intervention.

clopidogrel to prasugrel and 190(4.6\%) from prasugrel to clopidogrel (figure 1).

Modalities and appropriateness of switch: Aspirin and clopidogrel were introduced in the prehospital setting more often than prasugrel. After 2 days, the rate of clopidogrel use decreased due to the switch to prasugrel (figure 2). In the clopidogrel group, $48 \%$ of patients received a loading dose of $300 \mathrm{mg}$ and $30 \%$ received $600 \mathrm{mg}$ or more. When prasugrel was used as the first thienopyridine, a loading dose of $60 \mathrm{mg}$ was given in $64 \%$, but when patients were switched to prasugrel, only $8.3 \%$ receive a loading dose (table 1 ).

At admission, eligibility for prasugrel ranged from $42.9 \%$ to $59.6 \%$ in the groups treated with prasugrel at any time. Non-eligibility for prasugrel in the clopidogrel-only group mainly reflected the high proportion of patients older than 75 years $(40.4 \%)$, and without a definite indication for PCI $(100 \%-28.3 \%$ $=71.7 \%$ ). Among patients with a switch from clopidogrel to prasugrel, 9 had stent thrombosis during hospitalisation and among those with a switch from prasugrel to clopidogrel, 19 had a major bleeding event. At discharge, eligibility for prasugrel was $82.1-86.1 \%$ in the groups treated with prasugrel at any time. Therefore, appropriateness of the switch was high $(86 \%)$ from clopidogrel to prasugrel, but low (20\%) from prasugrel to clopidogrel. In addition, $39.4 \%$ in the clopidogrel-only group would have been eligible for a switch from clopidogrel to prasugrel and $16.4 \%$ in the prasugrel-only group would have been eligible for a switch from prasugrel to clopidogrel (table 1).

Predictors of switching: Compared with patients who received prasugrel at any time (ie, patients with a switch in thienopyridines or those treated with prasugrel alone), those treated with clopidogrel alone were older, more often women, more often had NSTEMI, more comorbidities, a higher GRACE risk score at admission and higher in-hospital and 1 year mortality (table 2).
Independent predictors of a switch were presentation with STEMI, admission to a non-cardiology emergency unit, history of previous PCI, lower quartile of age, body weight $>60 \mathrm{~kg}$, no cardiac arrest, no stroke, no anaemia and no renal dysfunction (figure 3). The model had adequate discrimination ( $(\mathrm{c}-\mathrm{stat}=0.77)$ and calibration $(\mathrm{p}$ value for the Hosmer-Lemeshow test $=0.45$ ).

Switch and quality of care. A significant interaction was observed between the centre and the rate of switching ( $\mathrm{p}=0.006)$. Among the 213 participating centres, 59 (28\%) never performed a switch. Four categories of centres were defined according to their switching rates: from $0 \%$ to $7 \%$ $(\mathrm{n}=75)$, from $8 \%$ to $18 \% \quad(\mathrm{n}=51)$, from $19 \%$ to $33 \%$ $(n=46)$ and $>33 \%(n=41)$. With increasing switch categories, there was a trend towards higher rates of use of coronary angiography, GPIIbIIIa inhibitors, radial access, reperfusion (for patients with STEMI, either by primary PCI or thrombolysis), timely reperfusion, and DAPT, ACE inhibitors and statins at discharge. As a result, there was a significant trend towards an increase in the composite indicator (for all MI and for STEMI) with higher rates of switching (table 3 and figure 4).

\section{DISCUSSION}

Our results provide insights into the rates and modalities of switching between thienopyridines, and raise questions about the appropriateness of switching drugs when the initial thienopyridine choice appears suboptimal.

\section{Modalities and rates of switching}

A switch was performed in $21.2 \%$, and more often from clopidogrel to prasugrel than vice versa. Thus, switching thienopyridines from a less potent to a more potent inhibitor is common practice. The modalities of prescription of thienopyridines at admission and at discharge after ACS were previously investigated in a study from 2012 based on data from the GRAPE registry. ${ }^{9}$ At 
Table 3 Patient characteristics and management according to the rate of switch by centre

\begin{tabular}{|c|c|c|c|c|c|}
\hline & $\begin{array}{l}\text { Switch rate } \\
0-7 \%\end{array}$ & $\begin{array}{l}\text { Switch rate } \\
7-18 \%\end{array}$ & $\begin{array}{l}\text { Switch rate } \\
18-33 \%\end{array}$ & $\begin{array}{l}\text { Switch rate } \\
>33 \%\end{array}$ & $\begin{array}{l}\text { p Value } \\
\text { (trend) }\end{array}$ \\
\hline Number of centres & 75 & 51 & 46 & 41 & \\
\hline Number of patients & 454 & 1146 & 975 & 1061 & \\
\hline Number of beds & $884 \pm 660$ & $889 \pm 768$ & $893 \pm 665$ & $802 \pm 601$ & 0.54 \\
\hline Cathlab on site centres & $660(67 \%)$ & $841(73 \%)$ & $691(71 \%)$ & $755(71 \%)$ & 0.09 \\
\hline Cardiac surgery on site & $320(32 \%)$ & $521(46 \%)$ & $533(55 \%)$ & $372(35 \%)$ & $<0.001$ \\
\hline Hospital stay (days) & $8 \pm 7$ & $7 \pm 7$ & $8 \pm 7$ & $8 \pm 7$ & $0.65^{\star}$ \\
\hline ICCU stay (days) & $5 \pm 4$ & $4 \pm 4$ & $4 \pm 4$ & $4 \pm 4$ & $0.35^{\star}$ \\
\hline Switch (all) & $25(1 \%)$ & $144(13)$ & $254(26)$ & $445(42)$ & $<0.001$ \\
\hline Switch (clopidogrel to prasugrel) & $15(1.5 \%)$ & $108(10)$ & $199(21)$ & $256(37)$ & $<0.001$ \\
\hline Switch (prasugrel to clopidogrel) & $10(1 \%)$ & $36(3)$ & $55(9)$ & $89(13)$ & $<0.001$ \\
\hline Male gender & $297(65 \%)$ & $845(74 \%)$ & $713(73 \%)$ & $780(73 \%)$ & 0.006 \\
\hline Age & $66 \pm 14$ & $64 \pm 14$ & $64 \pm 14$ & $64 \pm 14$ & $0.12^{*}$ \\
\hline Elderly & $648(34 \%)$ & $333(29 \%)$ & $288(30 \%)$ & $286(27 \%)$ & 0.008 \\
\hline GRACE risk score & $143 \pm 35$ & $140 \pm 36$ & $140 \pm 36$ & $146 \pm 35$ & $0.35^{\star}$ \\
\hline LVEF & $54 \pm 11$ & $51 \pm 11$ & $50 \pm 11$ & $52 \pm 12$ & $0.15^{\star}$ \\
\hline Body weight & $73 \pm 16$ & $77 \pm 14$ & $77 \pm 15$ & $77 \pm 14$ & $0.20^{\star}$ \\
\hline Radial access & $570(63 \%)$ & $763(72 \%)$ & $715(77 \%)$ & $847(84 \%)$ & $<0.001$ \\
\hline GPIIbIlla & $284(29 \%)$ & $410(36 \%)$ & $345(35 \%)$ & $460(43 \%)$ & $<0.001$ \\
\hline Coronary angiogram during stay & $912(92 \%)$ & $1069(93 \%)$ & $939(96 \%)$ & $1021(96 \%)$ & $<0.001$ \\
\hline Reperfusion (STEMI) & $383(76 \%)$ & $472(76 \%)$ & $441(80 \%)$ & $546(84 \%)$ & $<0.001$ \\
\hline Primary PCI (STEMI) & $320(63 \%)$ & $367(59 \%)$ & $384(69 \%)$ & $430(66 \%)$ & 0.001 \\
\hline Thrombolysis (STEMI) & $34(3.4 \%)$ & $64(5.6 \%)$ & $39(4.0 \%)$ & $68(6.4 \%)$ & 0.01 \\
\hline DAPT at discharge & $812(85 \%)$ & $980(88 \%)$ & $826(88 \%)$ & $911(89 \%)$ & 0.01 \\
\hline$\beta$-Blockers at discharge & $834(87 \%)$ & $967(87 \%)$ & $797(85 \%)$ & $898(88 \%)$ & 0.29 \\
\hline ACEI at discharge & $595(62 \%)$ & $809(73 \%)$ & $659(70 \%)$ & $1024(76 \%)$ & $<0.001$ \\
\hline Statins at discharge & $863(90 \%)$ & $1018(91 \%)$ & $872(93 \%)$ & $950(93 \%)$ & 0.002 \\
\hline Composite score & $0.76 \pm 0.24$ & $0.80 \pm 0.22$ & $0.81 \pm 0.21$ & $0.82 \pm 0.20$ & $<0.001^{*}$ \\
\hline Composite score (STEMI) & $0.83 \pm 0.15$ & $0.84 \pm 0.14$ & $0.84 \pm 0.14$ & $0.85 \pm 0.13$ & $<0.02^{*}$ \\
\hline BARC $3 A$ & $18(1.8 \%)$ & $26(2.3 \%)$ & $9(0.9 \%)$ & $13(1.2 \%)$ & 0.06 \\
\hline BARC 3B & $22(2.2 \%)$ & $34(3.0 \%)$ & $13(1.3 \%)$ & $25(2.4 \%)$ & 0.53 \\
\hline BARC 3C & 0 & $1(0.1 \%)$ & 0 & $1(0.1 \%)$ & 0.52 \\
\hline Transfusion & $39(3.9 \%)$ & $41(3.6 \%)$ & $30(3.1 \%)$ & $25(2.4 \%)$ & 0.03 \\
\hline $\mathrm{Hb}$ drop of $3-5 \mathrm{~g} / \mathrm{dL}$ & $81(8.2 \%)$ & $79(6.9 \%)$ & $79(8.1 \%)$ & $77(7.3 \%)$ & 0.67 \\
\hline $\mathrm{Hb}$ drop $\geq 5 \mathrm{~g} / \mathrm{dL}$ & $21(2.1 \%)$ & $27(2.9 \%)$ & $12(1.2 \%)$ & $21(1.9 \%)$ & 0.41 \\
\hline In-hospital mortality & $25(2.5 \%)$ & $33(2.9 \%)$ & $34(3.5 \%)$ & $33(3.1 \%)$ & 0.33 \\
\hline Stent thrombosis & $4(0.4 \%)$ & $6(0.5 \%)$ & $6(0.6 \%)$ & $5(0.5 \%)$ & 0.79 \\
\hline Reinfarction & $10(1.0 \%)$ & $9(0.8 \%)$ & $9(0.9 \%)$ & $16(1.5 \%)$ & 0.23 \\
\hline Combined end point & $49(5.0 \%)$ & $66(5.7 \%)$ & $51(5.2 \%)$ & $70(6.6 \%)$ & 0.17 \\
\hline
\end{tabular}

the time, ticagrelor was already available, which considerably increased the number of possible combinations of treatment. The GRAPE study used a similar definition of appropriate P2Y12 inhibitor treatment as in our study, and their findings are also in line with those from the FAST MI registry; namely, at admission, initial selection was considered appropriate in $45.8 \%$, less preferable in $47.2 \%$ and inappropriate in $6.6 \%$. In the majority of cases, an initially less-preferable selection was due to prescription of clopidogrel when in fact the patient was eligible for prasugrel or ticagrelor. Switches in therapy made it possible to achieve appropriate prescription in $64.1 \%$ at discharge. Our results are in line with those from the merged Acute Coronary Treatment and Intervention Outcomes Network Registry-Get with the Guidelines and CathPCI registry, where, among 47040 patients, a switch from clopidogrel was performed in $5.2 \%$ and from prasugrel to clopidogrel to prasugrel in $11.5 \% .{ }^{4}$ Analysis of the first dose of thienopyridine in our study showed that half the patients who were switched did not receive a loading dose for the second thienopyridine. This prudent attitude is coherent with published data showing greater platelet inhibition after a switch from clopidogrel to prasugrel in stable ${ }^{10} 11$ and unstable patients, ${ }^{12} 13$ compared with clopidogrel alone, regardless of the loading ${ }^{13}$ or maintenance ${ }^{11-13}$ doses. 
Figure 4 Rates of quality indicators across categories of centres (according to the rate of switch). DAPT, dual antiplatelet therapy; betab: $\beta$-blockers, ACEI, ACE inhibitors; dis, discharge; composite, composite indicator calculated using opportunity scoring (one point by applicable indicator divided by the number of applicable indicators);

composite_st, composite indicator

for patients with ST elevation

myocardial infarction (including

primary percutaneous coronary intervention or within 60 min by thrombolysis). reperfusion within 120 min by

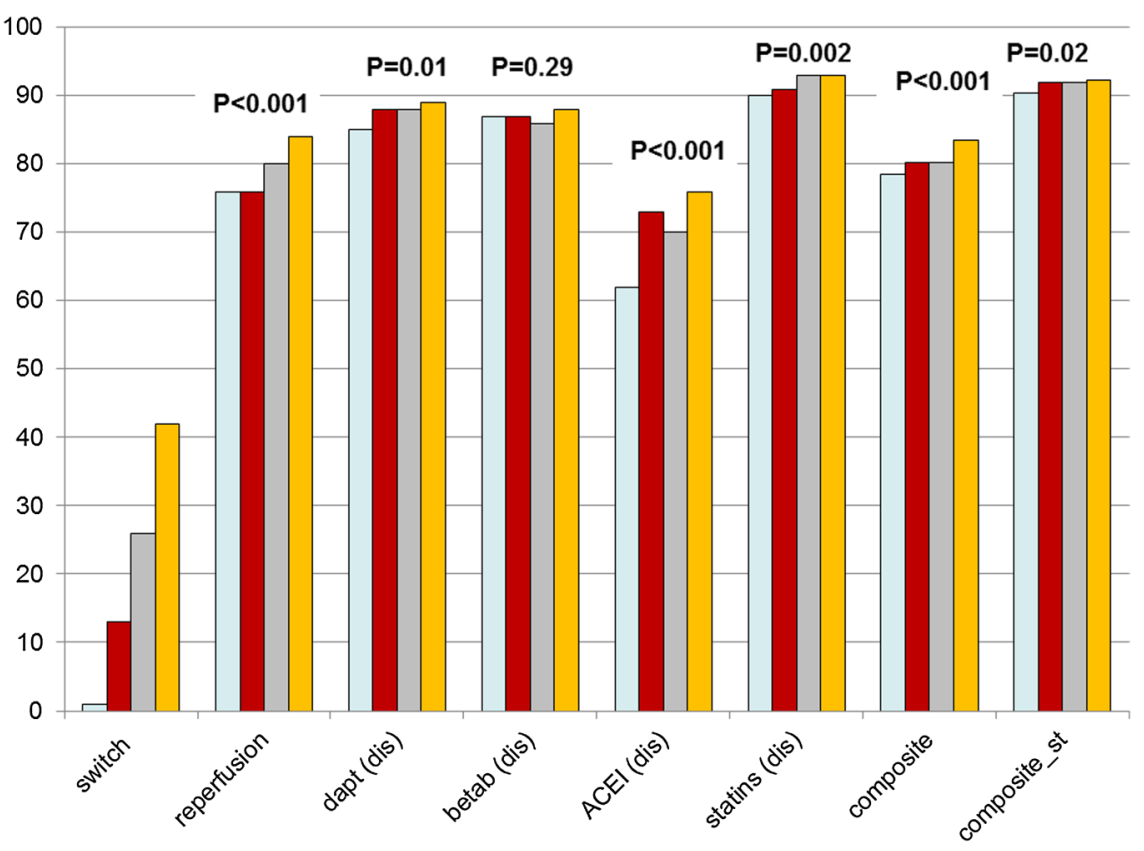

\section{Reasons for switching}

Our results suggest that the decision to switch was based on three main reasons: (1) the need to tailor platelet inhibition according to an in-hospital adverse event, (2) compliance with the labelling of prasugrel based on information not available at admission and (3) the expectation of better long-term clinical outcome by changing the thienopyridine, according to the results of the TRITON and TRILOGY studies.

A small proportion of switches were explained by in-hospital complications. Indeed, $19(10 \%)$ patients had a major bleeding and were switched from prasugrel to clopidogrel, while $9(1.3 \%)$ patients with stent thrombosis were switched from clopidogrel to prasugrel. The second explanation for a switch was compliance with the labelling of prasugrel and this largely explained the switching from prasugrel to clopidogrel. The last explanation for a switch was the expectation of better outcomes with a change from clopidogrel to prasugrel based on the results comparing clopidogrel and prasugrel.

Switching from clopidogrel to a more potent inhibitor (ticagrelor) was shown to be effective in the PLATO trial, without any apparent excess of events, ${ }^{14}$ and is recommended by guidelines. ${ }^{15-18}$ This explained a large proportion of the switches from clopidogrel to prasugrel. In this group, the appropriateness of switching practices was high, but did not reach $100 \%$. Nevertheless, although a small proportion of patients were not eligible for prasugrel, none had a strong contraindication, such as previous stroke or TIA.

The predictors for a switch were analysed globally, without distinguishing between directions of the switch, as in the reports by Bagai et $a .^{3}{ }^{4}$ The results suggest that a switch was not used to correct initial misuse of prasugrel, since older age, previous stroke and low body weight were associated with a low switch rate.

\section{Switch use and quality of care}

A switch from one drug to another, when the initial choice seems suboptimal, is usually considered as a positive action. In this view, switching thienopyridines for a more appropriate treatment might thus be considered to be good medical practice. There was a trend towards higher scores on quality indicators with increasing rates of switching, as shown by the higher rates of reperfusion, greater avoidance of complications (eg, use of radial access) and more compliance with guidelines for discharge treatment across categories of centres. Given that centres with a low rate of switching were also the centres that performed less well in terms of application of guidelines for reperfusion and discharge medication, it is unlikely that the low switch rate is a reflection of excellent initial treatment choices in these centres.

According to current methodology for the definition cannot per se be considered as an indicator of quality of care. Conversely, the appropriateness of the thienopyridine during hospitalisation and at discharge could be used as an indicator of quality since the use of prasugrel or ticagrelor instead of clopidogrel in eligible patients is evidence-based and supported by a IB recommendation in the European Society of Cardiology (ESC) guidelines; its assessment is most likely feasible.

\section{Study limitations}

Our findings, although resulting from a large cohort, are derived from observational analyses, which are subject to well-known limitations. First among these is of performance measures ${ }^{19}$ a switch in thienopyridines 152021 furthermore, it is interpretable, actionable and 
the potential for confounding by measured or unmeasured variables, which cannot be completely ruled out. Therefore, caution is advised in interpreting these results. Second, our 'quality indicators' are only rates of use and do not consider potential contraindications. Third, the term 'appropriate' was used to describe whether the prescriptions at discharge were in accordance with the labelling for each drug, in view of the patient's characteristics. This should under no circumstances be construed to imply superiority of either treatment. Lastly, owing to the retrospective nature of this study, the exact reasons for switching were not recorded, but simply deduced from the clinical characteristics of the patients. For example, it is possible that for the assessment of eligibility, certain justified contraindications to one or other therapy were not recorded.

\section{CONCLUSION}

The findings of the FAST-MI registry underline the complexity of choosing appropriate thienopyridine treatment in routine practice in patients with AMI when only clopidogrel and prasugrel are available. During hospitalisation, in a substantial proportion of patients, the thienopyridine initially prescribed is considered to have been suboptimal, leading to a switch to another drug. As applied in the FAST-MI registry, the switch in thienopyridines was performed according to the labelling of the drugs, and was associated with higher rates of quality of care indicators.

\author{
Author affiliations \\ ${ }^{1}$ Department of Cardiology, University Hospital Jean Minjoz, Besancon, France \\ ${ }^{2}$ Department of Cardiology, European Hospital of Georges Pompidou, Paris, \\ France \\ ${ }^{3}$ Département de Cardiologie, Centre Hospitalo-Universitaire Nord, Marseille, \\ France \\ ${ }^{4}$ Institut de Cardiologie (APHP), INSERM CMR937 and Univ Paris 6, Pitié- \\ Salpêtrière University Hospital, Paris, France \\ ${ }^{5}$ Department of Cardiology, Gabriel Montpied Hospital, Clermont-Ferrand, \\ France \\ ${ }^{6}$ University of Auvergne, ERIM-EA3295, Clermont-Ferrand, France \\ ${ }^{7}$ Centre Hospitalier Général, Vichy, France \\ ${ }^{8}$ Department of Cardiologie, Chu Montpellier, Montpellier, France \\ ${ }^{9}$ Service de Cardiologie, Clinique mutualiste des Eaux Claires, Grenoble, \\ France \\ ${ }^{10}$ Department of Cardiology, University Hospital Rangueil, Toulouse, France \\ ${ }^{11}$ Université Pierre et Marie Curie - Paris 6, Paris, France \\ ${ }^{12}$ Department of Cardiology, Hôpital Européen Georges Pompidou, Université \\ René Descartes, Paris, France
}

Contributors ND and TS were involved in study conception and design. All authors were involved in data collection. FS, NM and ND were involved in statistical analysis. FS, NM, ND and TS were involved in drafting of the manuscript. All authors were involved in critical revision of the manuscript, and approval of final version for publication.

Funding FAST-MI is a registry of the French Society of Cardiology, supported by the Société Française de Médecine d'Urgence, SAMU de France, the Collège National des Cardiologues des Hôpitaux and the Collège National des Cardiologues Français. The study was sponsored by the French Society of Cardiology and funded by unrestricted grants of the following companies: MSD, AstraZeneca, the Daiichi-SankyoEli-Lilly alliance, GlaxoSmithKline, Novartis and sanofi-aventis.
Competing interests FS reports research contracts and consulting with sanofi-aventis, astra, MSD, Bristol Myers Squibb, Amgen and Pfizer. TS has received research grants from Pfizer and Servier for the FAST-MI registry; served as a board member for Bayer; and has given lectures to Sanofi and Lilly. ND reports grants, personal fees and non-financial support from Amgen, grants, personal fees and non-financial support from AstraZeneca, grants and personal fees from Daiichi Sankyo, grants, personal fees and non-financial support from Eli Lilly, personal fees from BMS, personal fees from GSK, grants and personal fees from MSD, grants and personal fees from Novartis, personal fees from Novo-Nordisk, grants and personal fees from Pfizer, personal fees from Roche, grants, personal fees and non-financial support from Sanofi, and personal fees and non-financial support from Servier, outside the submitted work.

\section{Patient consent Obtained.}

Ethics approval Committee for the Protection of Human Subjects of Saint Louis University Hospital Paris Ile de France IV, Paris, France.

Provenance and peer review Not commissioned; externally peer reviewed.

Data sharing statement No additional data are available.

Open Access This is an Open Access article distributed in accordance with the Creative Commons Attribution Non Commercial (CC BY-NC 4.0) license, which permits others to distribute, remix, adapt, build upon this work noncommercially, and license their derivative works on different terms, provided the original work is properly cited and the use is non-commercial. See: http:// creativecommons.org/licenses/by-nc/4.0/

\section{REFERENCES}

1. Schiele F, Meneveau N. The role of the interventional cardiologist in selecting antiplatelet agents in acute coronary syndromes: a 10-question strategy. Eur Heart J Acute Cardiovasc Care 2012;1:170-6.

2. Azmoon S, Angiolillo DJ. Switching antiplatelet regimens: alternatives to clopidogrel in patients with acute coronary syndrome undergoing $\mathrm{PCl}$ : a review of the literature and practical considerations for the interventional cardiologist. Catheter Cardiovasc Interv 2013;81:232-42.

3. Bagai A, Peterson ED, Honeycutt E, et al. In-hospital switching between adenosine diphosphate receptor inhibitors in patients with acute myocardial infarction treated with percutaneous coronary intervention: insights into contemporary practice from the TRANSLATE-ACS study. Eur Heart $J$ Acute Cardiovasc Care 2015;4:499-508.

4. Bagai A, Wang Y, Wang TY, et al. In-hospital switching between clopidogrel and prasugrel among patients with acute myocardial infarction treated with percutaneous coronary intervention: insights into contemporary practice from the national cardiovascular data registry. Circ Cardiovasc Interv 2014;7:585-93.

5. Hanssen M, Cottin Y, Khalife K, et al. French Registry on Acute ST-elevation and non ST-elevation Myocardial Infarction 2010. FAST-MI 2010. Heart 2012;98:699-705

6. Flynn MR, Barrett C, Cosio FG, et al. The Cardiology Audit and Registration Data Standards (CARDS), European data standards for clinical cardiology practice. Eur Heart J 2005;26:308-13.

7. Wiviott SD, Braunwald E, McCabe $\mathrm{CH}$, et al. Prasugrel versus clopidogrel in patients with acute coronary syndromes. $N$ Engl J Med 2007;357:2001-15.

8. Roe MT, Armstrong PW, Fox KA, et al. Prasugrel versus clopidogrel for acute coronary syndromes without revascularization. $N$ Engl Med 2012;367:1297-309.

9. Alexopoulos D, Goudevenos JA, Xanthopoulou I, et al. Implementation of contemporary oral antiplatelet treatment guidelines in patients with acute coronary syndrome undergoing percutaneous coronary intervention: a report from the GReek AntiPlatelet rEgistry (GRAPE). Int J Cardiol 2013;168:5329-35.

10. Payne CD, Li YG, Brandt JT, et al. Switching directly to prasugre from clopidogrel results in greater inhibition of platelet aggregation in aspirin-treated subjects. Platelets 2008;19:275-81.

11. Wiviott SD, Trenk D, Frelinger AL, et al. Prasugrel compared with high loading- and maintenance-dose clopidogrel in patients with planned percutaneous coronary intervention: the Prasugrel in Comparison to Clopidogrel for Inhibition of Platelet Activation and Aggregation-Thrombolysis in Myocardial Infarction 44 trial. Circulation 2007;116:2923-32. 
12. Angiolillo DJ, Saucedo JF, Deraad R, et al. Increased platelet inhibition after switching from maintenance clopidogrel to prasugrel in patients with acute coronary syndromes: results of the SWAP (SWitching Anti Platelet) study. J Am Coll Cardiol 2010;56:1017-23.

13. Montalescot G, Sideris G, Cohen R, et al. Prasugrel compared with high-dose clopidogrel in acute coronary syndrome. The randomised, double-blind ACAPULCO study. Thromb Haemost 2010;103:213-23.

14. Wallentin L, Becker RC, Budaj A, et al. Ticagrelor versus clopidogrel in patients with acute coronary syndromes. $N$ Engl $\mathrm{J}$ Med 2009;361:1045-57.

15. Hamm CW, Bassand JP, Agewall S, et al. ESC guidelines for the management of acute coronary syndromes in patients presenting without persistent ST-segment elevation: the Task Force for the management of acute coronary syndromes (ACS) in patients presenting without persistent ST-segment elevation of the European Society of Cardiology (ESC). Eur Heart J 2011;32:2999-3054.

16. O'Gara PT, Kushner FG, Ascheim DD, et al. 2013 ACCF/AHA guideline for the management of ST-elevation myocardial infarction: a report of the American College of Cardiology Foundation/American Heart Association Task Force on Practice Guidelines. Circulation 2013;127:e362-425.

17. Steg PG, James SK, Atar D, et al. ESC guidelines for the management of acute myocardial infarction in patients presenting with ST-segment elevation: the Task Force on the management of
ST-segment elevation acute myocardial infarction of the European Society of Cardiology (ESC). Eur Heart $J$ 2012;33:2569-619.

18. Wright RS, Anderson JL, Adams CD, et al. 2011 ACCF/AHA focused update of the guidelines for the management of patients with unstable angina/non-ST-elevation myocardial infarction (updating the 2007 guideline): a report of the American College of Cardiology Foundation/American Heart Association Task Force on Practice Guidelines. Circulation 2011;123:2022-60.

19. Spertus JA, Bonow RO, Chan $\mathrm{P}$, et al. ACCF/AHA new insights into the methodology of performance measurement: a report of the American College of Cardiology Foundation/American Heart Association Task Force on performance measures. Circulation 2010;122:2091-106.

20. Steg PG, James SK, Atar D, et al. ESC guidelines for the management of acute myocardial infarction in patients presenting with ST-segment elevation. Eur Heart J 2012;33:2569-619.

21. Windecker S, Kolh P, Alfonso F, et al. 2014 ESC/EACTS guidelines on myocardial revascularization: the Task Force on Myocardial Revascularization of the European Society of Cardiology (ESC) and the European Association for Cardio-Thoracic Surgery (EACTS) developed with the special contribution of the European Association of Percutaneous Cardiovascular Interventions (EAPCI). Eur Heart $J$ 2014;35:2541-619. 